\title{
The orthologue of the "acatalytic" mammalian ART4 in chicken is an arginine-specific mono-ADP-ribosyltransferase Andreas Grahnert ${ }^{1}$, Steffi Richter ${ }^{1}$, Fritzi Siegert ${ }^{1}$, Angela Berndt ${ }^{2}$ and Sunna Hauschildt*1
}

Address: ${ }^{1}$ University of Leipzig, Institute of Biology II, Department of Immunobiology, Talstrasse 33, 04103 Leipzig, Germany and ${ }^{2}$ Institute of Molecular Pathogenesis, Friedrich-Loeffler-Institute, Naumburger Str. 96a, 07743 Jena, Germany

Email: Andreas Grahnert - grahnert@rz.uni-leipzig.de; Steffi Richter - steffirichter83@gmx.de; Fritzi Siegert - siegert@uni-leipzig.de; Angela Berndt - angela.berndt@fli.bund.de; Sunna Hauschildt* - shaus@rz.uni-leipzig.de

* Corresponding author

Published: 14 October 2008

BMC Molecular Biology 2008, 9:86 doi:10.1 186/147/-2199-9-86

This article is available from: http://www.biomedcentral.com/147I-2199/9/86

(c) 2008 Grahnert et al; licensee BioMed Central Ltd.

This is an Open Access article distributed under the terms of the Creative Commons Attribution License (http://creativecommons.org/licenses/by/2.0), which permits unrestricted use, distribution, and reproduction in any medium, provided the original work is properly cited.
Received: 14 April 2008
Accepted: 14 October 2008

\begin{abstract}
Background: Human ART4, carrier of the GPI-(glycosyl-phosphatidylinositol) anchored Dombrock blood group antigens, is an apparently inactive member of the mammalian mono-ADPribosyltransferase (ART) family named after the enzymatic transfer of a single ADP-ribose moiety from $\mathrm{NAD}^{+}$to arginine residues of extracellular target proteins. All known mammalian ART4 orthologues are predicted to lack ART activity because of one or more changes in essential active site residues that make up the R-S-EXE motif. So far, no other function has been detected.
\end{abstract}

Results: Here we report the identification and characterisation of ART4 in chicken, which to our knowledge is the first true non-mammalian orthologue of a mammalian ART family member. The chicken ART4 gene has the same physical structure as its mammalian counterparts (three coding exons separated by two introns in phase 0 and phase I, respectively) and maps to a region of conserved linkage synteny on chromosome I. Its mRNA encodes a 289 amino acid protein with predicted $\mathrm{N}$-terminal signal peptide and C-terminal GPI-anchor sequences and $47 \%$ sequence identity to human ART4. However, in striking contrast to its mammalian orthologues, the chicken protein contains an intact R-S-EXE motif. Upon ectopic expression in C-33A cells, recombinant chicken ART4 localized at the cell surface as a GPI-anchored, highly glycosylated protein, which displayed arginine-specific ART activity (apparent $K_{m}$ of the recombinant protein for etheno-NAD ${ }^{+}$ $1.0 \pm 0.18 \mu \mathrm{M})$.

Conclusion: The avian orthologue of the "acatalytic" mammalian ART4 is a mono-ADPribosyltransferase with enzymatic activity comparable to that of other, catalytically active and GPIanchored members of the mammalian ART family.

\section{Background}

ART4 is structurally related to vertebrate ecto-ADP-ribosyltransferases (ARTs), which covalently modify extracel- lular substrates by transferring a single ADP-ribose residue from $\mathrm{NAD}^{+}$to a specific amino acid in the target protein $[1,2]$. 
The mammalian ART family which comprises five members (ART1 - ART5) has been extensively studied in mice and humans [3]. In contrast to humans, which lack ART2 expression due to the presence of a non-functional ART2 gene [4], two ART2 proteins are expressed in mice as a result of gene duplication [5]. Among the five known ARTs, only ART1, ART2 and ART5 exhibit arginine-specific enzyme activity. ART3 and ART4 appear to have lost their catalytic activity, most likely due to the non-conservative substitution of residues in the R-S-EXE motif, which is typically present in the active centre of arginine-specific ARTs [6].

So far, no evidence for a potential other function has emerged for either of the two "acatalytic" members of the mammalian ART family, except that human ART4 has previously been demonstrated to be identical with the polymorphic Dombrock blood group antigen expressed on erythrocytes as GPI (glycosyl-phosphatidylinositol)anchored glycoprotein $[7,8]$. In addition, we and others have shown that expression of the human ART4 gene can be induced by lipopolysaccharide, lipoteichoic acid and peptidoglycan in monocytes and alveolar epithelial cells [9-11].

Given the fact that the ART2 gene locus shows considerable genetic variation even among mammalian species (one active gene in rat, two active genes in mice versus one pseudogene in humans $[4,5,12])$, we sought to employ bioinformatic means to search for other ART4 orthologues not only in mammals but also in lower vertebrates. A tBLASTn search, in which the amino acid sequence of human ART4 was compared to entries in NCBI's nucleotide sequence databases dynamically translated in all reading frames, resulted in the detection of a predicted gene transcript in chicken that potentially encoded a protein "similar to Dombrock blood group carrier molecule". Intriguingly, this protein contained an intact R-S-EXE motif, which raised the possibility that it represented an active ART enzyme. As none of the ARTs identified in chicken so far $[13,14]$ was evolutionary related to mammalian ARTs, it was important to verify the orthologous relationship between the putative chicken and the human ART4 gene, before attempting to prove the enzymatic activity of its protein.

Here we report for the first time the existence of a GPIanchored ART4 in chicken, which, to our knowledge, represents also the first real orthologue of a member of the mammalian ecto-ART family in a non-mammalian species. Moreover, in contrast to its mammalian ART4 orthologues, chicken ART4 displays an arginine-specific monoADP-ribosyltransferase activity.

\section{Methods \\ Materials}

$\left.{ }^{32} \mathrm{P}\right]-\mathrm{NAD}^{+}(800 \mathrm{Ci} / \mathrm{mmole})$ was obtained from PerkinElmer LAS GmbH (Rodgau-Jugesheim, Germany). Oligonucleotides were synthesized by Invitrogen $\mathrm{GmbH}$ (Karlsruhe, Germany). Unless otherwise indicated materials used in this study were from the following manufacturers: Fermentas GmbH (St. Leon-Rot, Germany): E. coli DNA polymerase I, T4 DNA polymerase, T4 DNA ligase, Pfu-DNA polymerase, dNTP solution, RevertAid ${ }^{\mathrm{TM}} \mathrm{H}$ Minus M-MuLV reverse transcriptase, High Fidelity PCR Enzyme Mix, and CloneJET ${ }^{\text {тм} P C R ~ C l o n i n g ~ K i t ; ~ Q i a g e n ~}$ (Hilden, Germany): RNeasy Mini Kit; Invitrogen GmbH (Karlsruhe, Germany): TOPO TA Cloning Kit, 100 bp DNA ladder, pSecTagB plasmid, and Zeocin ${ }^{\mathrm{Tm}}$; NEB GmbH (Frankfurt/Main, Germany): RNase H, Quick Ligation Kit, PNGase F; Sigma-Aldrich GmbH (Taufkirchen, Germany): $1, N^{6}$-etheno-NAD ${ }^{+}$, Anti-Flag ${ }^{\circledR} \mathrm{M} 2$ antibody, AntiFlag $^{\circledast}$ M2 Affinity Gel, poly-L-arginine (molecular weight $5000-15000)$.

Sequencing was performed by GATC Biotech AG (Konstanz, Germany).

The animals of the study were neither infected nor manipulated otherwise and were kept as well as sacrificed considering the animal welfare and the International Guiding Principles for Biomedical Research. The chicks served exclusively as organ donors. Therefore, no permission was required for the use of the animals as regularised in $\$ 4$ (3) of the German Animal Welfare Act.

\section{Cell culture and transfection}

C-33A cells (human cervix carcinoma), a kind gift from Dr. Kurt Engeland (Frauenklinik, University of Leipzig, Germany) were cultured in Dulbecco's modified Eagle's medium (DMEM) supplemented with $10 \%(\mathrm{v} / \mathrm{v})$ fetal bovine serum, $2 \mathrm{mM}$ L-glutamine and antibiotics at $37^{\circ} \mathrm{C}$ and $10 \% \mathrm{CO}_{2}$. Transient transfections of C-33A cells were performed using $4 \mu \mathrm{l} \mathrm{FuGENE}{ }^{\circledast}$ HD (Roche Diagnostics GmbH, Mannheim, Germany) according to the manufacturer's instruction. Exponentially growing cells $\left(3.5 \times 10^{5} /\right.$ well) were plated in $2 \mathrm{ml}$ culture medium in 6 well plates. After $24 \mathrm{~h}$ they were transfected with $2 \mu \mathrm{g}$ expression plasmids or $2 \mu \mathrm{g}$ empty plasmids as a control. To obtain stably transfected cells they were incubated for four weeks with $250 \mu \mathrm{g} / \mathrm{ml}$ Zeocin $^{\mathrm{TM}}$. After staining with the anti-humanART4 or anti-Flag M2 antibodies high positive cells were enriched using a cell sorter (Becton Dickinson).

HD3 cells (chicken erythroblasts), a kind gift from Dr. Thomas Göbel (Institute for Animal Physiology, University of Munich) were cultured in RPMI 1640 medium supplemented with $8 \%(\mathrm{v} / \mathrm{v})$ fetal bovine serum, $2 \%(\mathrm{v} / \mathrm{v})$ chicken serum, $2 \mathrm{mM}$ L-glutamine and antibiotics at $37^{\circ} \mathrm{C}$ 
and $5 \% \mathrm{CO}_{2}$. Cells were maintained as suspension cultures $\left(1 \times 10^{5}\right.$ cells $\left./ \mathrm{ml}\right)$ and after three to four days cells were passaged by 1:10 dilution with fresh culture medium.

Human embryonic kidney (HEK-293-T) cells, a kind gift from Dr. Friedemann Horn (Molecular Immunology, University of Leipzig, Germany) were grown in Dulbecco's modified Eagle's medium (DMEM) supplemented with $10 \%(\mathrm{v} / \mathrm{v})$ fetal bovine serum, $2 \mathrm{mM}$ L-glutamine and antibiotics at $37^{\circ} \mathrm{C}$ and $10 \% \mathrm{CO}_{2}$. Cells were transfected as described [10]. To obtain stably transfected cells they were incubated for four weeks with $250 \mu \mathrm{g} / \mathrm{ml}$ Zeocin $^{\mathrm{TM}}$.

\section{RNA isolation and reverse transcription}

Total RNA was isolated from pieces of yolk sack (14 day old embryo, breed: Italian), from chicken bone marrow cells $\left(2 \times 10^{6}\right)$ (breed: German White Leghorn; German White Leghorn $\times$ Rhode Island Red) or from HD3 cells (2 $\times 10^{6}$ ) using the RNeasy Mini Kit according to the manufacturer's instruction. Reverse transcription was performed as described previously [9].

\section{PCR primers and PCR reaction}

Unless otherwise described, Table 1 shows the sequences of primers used in this study. PCR analysis (30 - 40 cycles) were carried out using cDNA from HD3 cells (chART4 fwd II/chART4 rev II or chART4 RACE3/3'UTR rev5) to amplify the chicken ART4 mRNA. PCR products were separated by electrophoresis on $1.5 \%(\mathrm{w} / \mathrm{v})$ agarose gels (FMC Bioproducts, Rockland, MA, U.S.A.) containing $1.25 \mu \mathrm{g} / \mathrm{ml}$ ethidium bromide and visualized under UV light.

\section{5 ' inverse RACE-PCR}

First strand synthesis was performed with total RNA isolated from the yolk sack of a 14 day old embryo. A total of $10 \mu \mathrm{l}$ (approx. $4 \mu \mathrm{g}$ ) was used to prepare cDNA by annealing RNA with $1 \mu \mathrm{l}(100 \mathrm{pmol})$ of gene-specific primer RT_2_chART4. After denaturation for $10 \mathrm{~min}$ at $70^{\circ} \mathrm{C}$ reverse transcription using RevertAid ${ }^{\mathrm{TM}} \mathrm{H}$ Minus M-MuLV reverse transcriptase at $37^{\circ} \mathrm{C}$ for 60 min was performed. An inactivation phase of $10 \mathrm{~min}$ at $70^{\circ} \mathrm{C}$ was followed by second strand synthesis, ring ligation, and inverse nested PCR amplification (primer pairs chART4 inverse fwd1/ RT_chART4 and chART4 inverse fwd2/chART4 inverse rev2 as described previously [15].

\section{3' RACE-PCR}

To amplify the 3'-end of chicken ART4 mRNA from HD3 cells, 3'RACE-PCR was performed according to Frohman et al. [16]. Briefly, $10 \mu$ l total RNA (approx. $4 \mu \mathrm{g}$ ) were reverse transcribed for $60 \mathrm{~min}$ at $37^{\circ} \mathrm{C}$ using RevertAid ${ }^{\mathrm{TM}}$ $\mathrm{H}$ Minus M-MuLV reverse transcriptase and the RT-RACEchick primer. Nested PCR (40 cycles) was performed using an adaptor-specific primer (RACE reverse II) and different forward primers (3'UTR fwd2, 3'UTR fwd3, and 3'UTR fwd4). PCR products were diluted 1:10 prior to the next PCR step.

Table I: List of primers used in this study

\begin{tabular}{ll}
\hline Primer & Sequence $\left(5^{\prime}-3^{\prime}\right)$ \\
\hline oligo dT 20 & TTT TTT TTT TTT TTT TTT TT \\
chART4 fwd II & GTC CTT GGG AGG ACT CCA G \\
chART4 rev II & AGA AAG CCA AGC AGT TCG TC \\
chART4 RACE3 & TGG GGA ACT ACA GCA AGT ACC \\
3'UTR rev5 & GGC CTT TTG TTC CTG AAG AG \\
RT_2_chART4 & TTT CCC TAC GTT GTC CTT GC \\
chART4 inverse fwdI & ACA TCC ACA GCA GGA AGG TC \\
RT_chART4 & AGC TTC CTG AGC CTT CTT CC \\
chART4 inverse fwd2 & ACC TAA CGA CAG CCA TCC AG \\
chART4 inverse rev2 & AAA TAG TCT CCC CGC TCC AG \\
RT-RACE-chick & GAT CTA GAG GTA CCG GAT CCT TTT TTT TTT TTT TTT TTV N \\
RACE reverse II & GAT CTA GAG GTA CCG GAT CC \\
chART4 Poly for & TGA GAA TTT TTG CCC AGC TC \\
chART4 Poly rev & AGA AAG CCA AGC AGT TCG TC \\
3'UTR fwd2 & CCT TCA GCA GCC TTT CTT TG \\
3'UTR fwd3 & TGC AGA TGG GTT ATT TTC ACC \\
3'UTR fwd4 & ACG GAA GTC TTC ACA TGT CC \\
GAPDH fwd & GTC AGC AAT GCA TCG TGC A \\
GAPDH rev & GGC ATG GAC AGT GGT CAT AAG A \\
chA4 realtime 3 & GTC CTC ATT CCC CCT TAT GA \\
chA4 realtime 5 & TTC TTG ATT CTT GAA GCT TC \\
\end{tabular}




\section{Quantitative real-time RT-PCR}

Different organs (lung, bone marrow, thymus, spleen, caecum, liver, bursa of Fabricius) from five-day-old chicken were stored in RNA-later (Qiagen, Hilden, Germany) until use. Total RNA was extracted using the RNeasy Mini Kit (Qiagen) and contaminating DNA was digested using the RNase-free DNase Set (Qiagen). RNA was eluted in $50 \mu \mathrm{l}$ RNase-free water per $20 \mathrm{mg}$ tissue, stored and analysed by spectral analysis (BioPhotometer, Eppendorf, Hamburg, Germany). Only samples with mRNA purity of about 2 (ratio E260/280) or above 2 (E260/230) were used. The quantity of mRNA was adjusted and the mRNA expression rates of ART4 (chA4 realtime3/chA4 realtime5) and GAPDH (GAPDH fwd/ GAPDH rev) was determined for each bird using the QuantiTect $^{\mathrm{TM}}$ SYBR $^{\circledast}$ Green one-step RT-PCR Kit (Qiagen). Amplification and detection of specific products were performed on a Mx3000P ${ }^{\text {TM }}$ real-time PCR equipment (Stratagene, La Jolla, CA) using the following temperature-time profile: one cycle at $50^{\circ} \mathrm{C}$ for $30 \mathrm{~min}, 96^{\circ} \mathrm{C}$ for $15 \mathrm{~min}$, and 45 cycles at $94^{\circ} \mathrm{C}$ for $30 \mathrm{~s}, 55^{\circ} \mathrm{C}$ for $30 \mathrm{~s}$ followed by $72^{\circ} \mathrm{C}$ for $30 \mathrm{~s}$. To check the specificity of amplification products, the dissociation curve mode was used (one cycle at $95^{\circ} \mathrm{C}$ for $1 \mathrm{~min}, 55^{\circ} \mathrm{C}$ for $30 \mathrm{~s}$ and $95^{\circ} \mathrm{C}$ for $30 \mathrm{~s}$ ) subsequent to amplification and the amplicons were sequenced. Final quantification was done using the comparative Ct-method and reported as relative gene expression to cDNA from bone marrow (calibrator). The threshold cycle number $(\mathrm{Ct})$ was calculated and the levels of chicken ART4 expression were normalized to GAPDH using the formula $2^{-\Delta \Delta \mathrm{Ct}}$ in which $\Delta \Delta \mathrm{Ct}=\Delta \mathrm{Ct}$ (sample) $\Delta \mathrm{Ct}$ (calibrator) with $\Delta \mathrm{Ct}$ as difference between Ct of target gene (chicken ART4) and $\mathrm{Ct}$ of housekeeping gene $(G A P D H)$.

\section{Cloning and sequencing of $P C R$ products}

PCR products were excised from agarose gels. The fragments were cloned using the TOPO TA cloning kit or the CloneJET ${ }^{\mathrm{TM}} \mathrm{PCR}$ Cloning kit according to the manufacturer's instruction. Plasmid DNA was purified using a GFX $^{\text {тм }}$ Micro Plasmid Prep Kit (Amersham Biosciences, Munich, Germany) and sequenced on both strands.

\section{Construction of a chicken ART4 expression plasmid}

DNA from $1 \times 10^{7}$ chicken bone marrow cells (German White Leghorn $\times$ Rhode Island Red) was isolated using standard procedures. The coding sequence of chicken ART4 was amplified using genomic DNA from chicken bone marrow cells with primers derived from [GenBank: AADN01052179]. PCRs were carried out using the High Fidelity PCR Enzyme Mix with primers amplifying the coding sequence of exon2 (fwd: 5'-GAC GAT GAC AAG TCC CAC CTT ATG ATG-3' and rev: 5'-CTT GAT TCT TGA AGC TTC CAA GAG CTG G-3') and exon3 (fwd: 5'-CCA GCT CTT GGA AGC TTC AAG AAT CAA G-3' and rev: GAC
TCG AGT CAT TGC TTG GCC AAG CAC-3'). The resulting PCR products (the sequences that are underlined represent complementary regions) were fused in a second PCR reaction using the following primer pair (fwd: 5'-TTG GTA CCG ACT ACA AGG ACG ACG ATG A-3' and rev: 5'-GAC TCG AGT CAT TGC TTG GCC AAG CAC-3') and the High Fidelity PCR Enzyme Mix. The chicken ART4 N-terminal signal peptide was exchanged by the Flag-tag (DYKDDDDK) (sequences of the primers that encode the Flagtag are highlighted in italics). The resulting PCR product was purified and used for Acc65I/XhoI cloning into the pSecTagB plasmid. The construct-encoded chicken ART4 protein sequence was identical to the predicted protein sequence of [GenBank: XM425453.1] except for a F267L polymorphism. The polymorphism ([GenBank: EU056570]) was located within the GPI-anchor signal peptide and should have no effect on the mature protein.

\section{Site-directed mutagenesis of human ART4}

Following oligonucleotides were used to mutate the Y-SKKE motif: Y187R_for 5'-GAG GTG CAT AGG AGG ACG AAG GAT-3' and Y187R_rev 5'-ATC CTT CGT CCT CCT ATG CAC CTC-3' for exchanging the tyrosine ${ }^{187}$ by an arginine and K242E_for 5'-TTC TCC CTC GAG AAG GAA GTC TTG-3' and K242E_rev 5'-CAA GAC TTC CTT CTC GAG GGA GAA G-3' for exchanging the lysine ${ }^{242}$ by a glutamate (the changes are underlined). PCR was performed using a human ART4 expression plasmid [10] as template $\left(20\right.$ cycles at $\left.57^{\circ} \mathrm{C}\right)$ and the following primer combinations: 1) Y187R_for and Expr_rev [10]; 2) K242E_for and Expr_rev; 3) Expr_3 [10] and Y187R_rev; 4) Expr_3 and K242E_rev. The products were separated on agarose gels, excised, and extracted from the gels. A second PCR was performed $\left(20\right.$ cycles, $54^{\circ} \mathrm{C}$ ) using the PCR products from combination 1 and 3 or combination 2 and 4 as templates together with Expr_3 and Expr_rev as primer. The resulting PCR products were cloned into the pcDNA3.1/Zeo (+) plasmid as described [10]. For each mutagenesis the insert was sequenced to verify the mutation and to exclude the presence of other mutations.

Treatment of C-33A cells with bacterial phospholipase $C$ C-33A cells $\left(4 \times 10^{7} / \mathrm{ml}\right)$ transfected with the chicken ART4 containing plasmid or the empty plasmid (pSecTagB) were suspended in PBS containing $5 \mathrm{U} / \mathrm{ml}$ Bacillus cereus phosphatidylinositol-specific phospholipase C (PI-PLC) (Invitrogen GmbH, Karlsruhe, Germany) and incubated for $60 \mathrm{~min}$ at $37^{\circ} \mathrm{C}$. Cells were washed three times prior to the detection of chicken ART by flow cytometry as described below.

\section{Treatment of chicken ART4 with PNGase F}

The supernatant of PI-PLC-treated C-33A cells transfected with a chicken ART4 containing plasmid was incubated in 
the presence or absence of PNGase F (20000 U/ml) according to the manufacturer's instruction.

\section{Expression of soluble, recombinant chicken ART4}

An N-terminal Flag-tagged chicken ART4 (amino acids 20 - 270) was cloned (Asp718I/XhoI) into the pSecTagB plasmid. HEK-293T cells were stably transfected with the plasmid and grown in serum-free Panserin PX40 medium (PAN-Biotech GmbH, Aidenbach, Germany) at $37^{\circ} \mathrm{C}$ and $10 \% \mathrm{CO}_{2}$. After $3-4$ days the supernatant was exchanged by fresh medium and purified using the Anti-Flag ${ }^{\circledast}$ M2 affinity gel according to the manufacturer instructions. Fractions $(1 \mathrm{ml})$ were lyophilized, reconstituted in $100 \mu \mathrm{l}$ aqua dest., combined and dialyzed against PBS.

This crude purified recombinant chicken ART4 was used for the ADP-ribosylation filter assay.

\section{Determination of $K_{m}$ values}

After incubating recombinant chART4 in the presence or absence of PNGase F (20000 U/ml) for $1 \mathrm{~h}$, ADP-ribosyltransferase activity was measured. The reaction mixture contained PBS (pH 7.4), poly-L-arginine $(1 \mathrm{mg} / \mathrm{ml})$, chART4 $(7 \mu \mathrm{g} / \mathrm{ml})$ and etheno-NAD ${ }^{+}(0.5,1,2$, and 5 $\mu \mathrm{M})$. Controls were run in the absence of chART4. The reaction was started by the addition of etheno-NAD+, and cleavage of etheno- $\mathrm{NAD}^{+}$was measured after $0.5,1.5,2.5$, $3.5,4.5,5.5,6.5,8,10,12,15,20$, and $30 \mathrm{~min}$ in the Fluorolog 3 spectrophotometer (Horiba Jobin Yvon GmbH, Munich, Germany) The excitation wavelength was $310 \mathrm{~nm}$ and the emission was recorded at $403 \mathrm{~nm}$. The fluorescence intensity was expressed as photons per second (CPS).

\section{ADP-ribosylation filter assay}

The assay was performed in a total of $100 \mu$ reaction mixture containing PBS ( $\mathrm{pH} 7.4$ ), $1 \mathrm{mM}$ ADP-ribose, $50 \mu \mathrm{M}$ $\left[{ }^{32} \mathrm{P}\right]-\mathrm{NAD}^{+}(10 \mu \mathrm{Ci} /$ assay $)$ in the presence or absence of $100 \mu \mathrm{g}$ poly-L-arginine and recombinant chicken ART4 $(0.7 \mu \mathrm{g})$ for $30 \mathrm{~min}$ at $37^{\circ} \mathrm{C}$. The reactions were terminated by adding $50 \mu \mathrm{l}$ of ice-cold BSA $(5 \mathrm{mg} / \mathrm{ml})$ followed by $1.2 \mathrm{ml} \mathrm{25 \% (w/v)} \mathrm{trichloroacetic} \mathrm{acid.} \mathrm{After} 45 \mathrm{~min}$ at $4{ }^{\circ} \mathrm{C}$ the resulting precipitates were recovered by centrifugation $(10 \mathrm{~min}$ at $3000 \times \mathrm{g})$. The pellets were resuspended in $250 \mu \mathrm{l}$ of $2 \mathrm{M} \mathrm{KOH}$, precipitated again and collected on Whatman GF/C glass-fibre filters. After washing, filters were counted by liquid scintillation spectrometry.

\section{Treatment of cells with etheno-NAD ${ }^{+}$}

Cells $\left(1 \times 10^{7} / \mathrm{ml}\right)$ were incubated in PBS for $30 \mathrm{~min}$ at $37^{\circ} \mathrm{C}$ with $200 \mu \mathrm{M}$ of etheno-NAD ${ }^{+}$. After adding a 20fold volume of PBS cells were washed three times before performing FACS- or Western Blot analysis.

\section{Antibodies and FACS analysis}

The anti-Flag M2 antibody, IgG1 and IgG2a isotype control antibodies were from Sigma-Aldrich. The anti ethenoadenosine specific antibody 1G4 (IgG2a) [17] was kindly provided by Dr. Friedrich Koch-Nolte (University Hospital Eppendorf, Hamburg, Germany). Cells were incubated with the respective $\mathrm{mAbs}$ for $30 \mathrm{~min}$ at $4^{\circ} \mathrm{C}$. After washing in PBS containing 10\% Haemaccel ${ }^{\circledR}$ (Hoechst, Frankfurt, Germany), and $0.1 \%$ sodium azide they were incubated for $30 \mathrm{~min}$ at $4^{\circ} \mathrm{C}$ with FITC-labelled goat-anti-mouse antibody (SIFIN, Berlin, Germany). After washing and fixation in $1 \%$ formaldehyde, cells were analysed on a FACScan flow cytometer (Becton Dickinson, San Jose, CA, U.S.A.).

\section{Western Blot analysis}

Western Blot analysis was carried out as described previously [18]. Cells $\left(1.5 \times 10^{7} / \mathrm{ml}\right)$ were suspended in lysis buffer (50 mM Tris/HCl pH 7.5, $150 \mathrm{mM} \mathrm{NaCl}, 1 \%$ (v/v) NP-40, 0.5\% (w/v) deoxycholate, $0.1 \%$ SDS (w/v) and cOmplete protease inhibitor cocktail (Roche, Mannheim, Germany)) and sonicated. Samples were run on a $12 \%$ SDS-polyacrylamid gel (MiniProtean II, BioRad GmbH) and transferred to polyvinylidene difluoride membranes (Amersham Biosciences, Munich, Germany). Membranes were probed with an anti-Flag M2 antibody $(10 \mu \mathrm{g} / \mathrm{ml})$, 1 G4 antibody (1/500) or anti- $\beta$-actin antibody $(1 / 5000$; clone AC-74, Sigma-Aldrich) and detected with a PODconjugated goat anti-mouse (1/20000 Sigma-Aldrich) secondary antibody using the Western Blotting Luminol Reagent (Santa Cruz Biotechnology, Santa Cruz, CA, U.S.A.) detection system.

\section{Data analysis}

Following programs were used: the standard nucleotidenucleotide BLAST [blastn] program [19] to screen the database of expressed sequence tags (dbEST) and the tBLASTn program to search translated nucleotide database using a protein query [20], SIM4 software [21] to align cDNA sequences with the genomic DNA sequence, CLUSTAL W software [22] for multiple amino acid alignment, and both SignalP 3.0 [23] and GPI-SOM [24] program for prediction of cellular localization and membrane anchorage, respectively.

\section{Results}

\section{Identification of an ART4-related gene in chicken}

In order to locate ART4-related genes in species other than mammals, we made use of the tBLASTn program, which compares a protein query sequence to nucleotide sequences dynamically translated in all six reading frames. A search of the National Center for Biotechnology Information (NCBI) "nr" nucleotide database with the human or mouse ART4 protein sequence uncovered a putative chicken gene transcript of 870 nucleotides that translated 
into a 289 amino acid protein "similar to Dombrock blood group carrier molecule" ([GenBank: XM425453.1 GI:50729203, VRT 28-JUL-2004]). This record had been generated by "automated computational analysis" of a genomic contig ([GenBank: NW001471513]) on chicken chromosome 1, which resulted in the prediction of an ART4-related gene composed of three coding exons. As in mammalian ART4 genes, the second exon encoded the major part of the protein, but different from the situation in mammals, it also coded for an intact R-S-EXE motif indicative of a functional catalytic domain of an argininespecific ADP-ribosyltransferase [6]. Incidentally, [GenBank: XM425453.1] was since removed from the "nr" database and on 06-Nov-2006 replaced by [GenBank: XM425453.2 GI:118082577]. (The protein encoded by the latter transcript differs at its C-terminus from the earlier version, because the new gene prediction lacks the third exon. As a consequence, the open reading frame in ex2 ends shortly after the ex2-intron2 junction predicted in the first record. Thus, [GenBank: XM425453.2] could reflect a splice variant.) To substantiate the presence of an active ART4-related gene in chicken, RT-PCR was performed on total RNA from HD3 cells (a chicken erythroblast cell line) with primers, designed to amplify the complete coding and additional flanking sequences of the trancript shown in [GenBank: XM425453.1]. A weak PCRproduct of approx. 950 base pairs was obtained (data not shown, [GenBank: EU269858]). It corresponded to the transcript predicted in the original [GenBank: XM425453.1] entry, thus, verifying the existence of an avian ART gene with three coding exons as found in mammalian ART4 genes. Using the BLASTP program [25] to compare the amino acid sequence of the chicken protein with that of each member of the ART family in men and mice, the highest degree of sequence identity exhibited the ART4 orthologues, with 47\% identity and 65\% similarity between chicken and human or $45 \%$ identity and 64\% similarity between chicken and mouse (Fig. 1). Figure $2 \mathrm{~A}$ shows the actual amino acid sequence alignment of the putative chicken ART4 with its presumed counterparts in mouse and man. As noted before, only the chicken protein contains an intact R-S-EXE motif. Note that in all three ARTs the X within the EXE tripeptide is a lysine $(\mathrm{K})$.

\section{Phylogentic relatedness of ART4 in chicken and mammals} Having demonstrated the existence of an apparently ART4-related gene in the chicken genome, we wanted to establish its phylogenetic relatedness with mammalian genes by analysing its location on chromosome 1 with respect to the presence and order of genes surrounding it. Employing NCBI's map viewer http://www.ncbi.nlm.nih. gov/mapview/ and tBLASTn searches revealed that the chicken gene mapped to a region syntenic to the portion

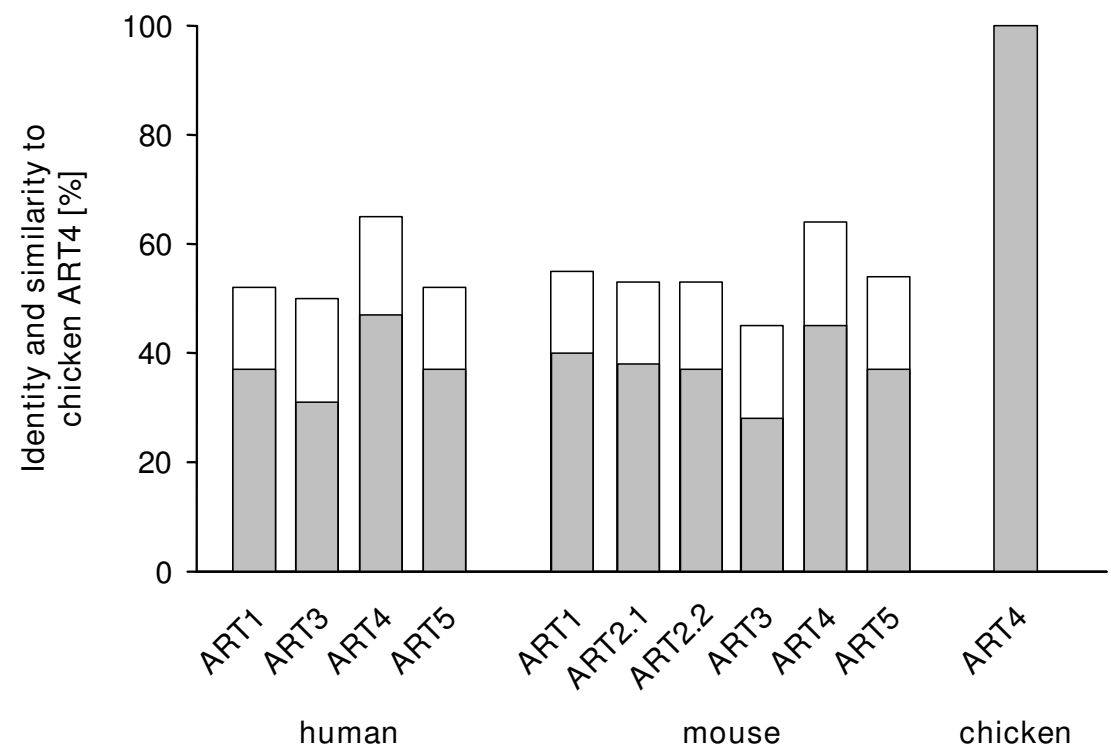

\section{Figure I}

Percentage amino acid similarity between members of the human and mouse ART family and chicken ART4. The BLASTP program [25] was used to compare the amino acid sequences of the chicken protein with that of each member of the ART family in men and mice. Shown are the \% identity (grey bars) and similarity (identity and conservative substitutions; white bars) of the proteins. 
A

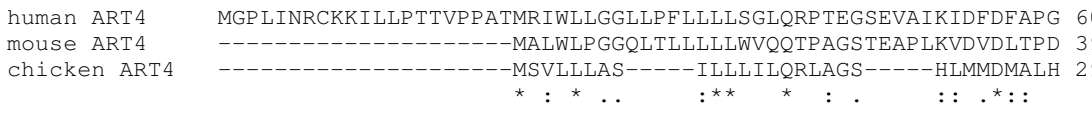

human ART4 SFDD Y Y Y GCSKQVMEKLTQGDYFTKDIEAQKNYFRMWQKAHLAWLNQGKVLPQNMTTTHA 120 mouse ART4 SEDDYYGCSEQMVEELNQGDYFIKEVDTHKYYSRAWQKAHLTWLNQAKALPESMTPVHA 99 chicken ART4 SFDD'RYGCREQMMEELERDPFEREIAASKNYSSLWKKAQEALLKSSVGLLREMHDSHA 89

human ART4 mouse ART4 chicken ART4

VAILFYTLNSNVHSDFTRAMASVARTPQQYERSFHFKYLHYYLTSAIQLLRKDSIMENGT 180 VAIVVFTLNLNVSSDLAKAMARAAGSPGQYSQSFHFKYLHYYLTSAIQLLRKDSSTKNGS 159 TALMAYTMNSS LHSQLNWATSTAGRSPEQYRHNFSFKYFHFYLTTAIQIMKQWQSSKDNV 149

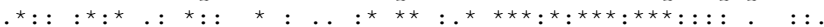

---LCYEVHYRTKDVHFNAYTGATIRFGQF LSTSLLKEEAQEFGNQTLFTIFTCLGAPVQ 237 ---LCYKVYHGMKDVS I GANVGST IRFGQF LSASLLKEETRVSGNQTLFTIFTCLGASVQ 216 chicken ART4 GKRHCYRVHRGVKDLYIKATVGSMVRFGRFTSTSRLWNEAQKFGNETLFTVTTCLGAAMQ 209

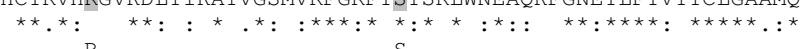
$\mathrm{R}$ $\mathrm{S}$

human ART4 mouse ART 4 chicken ART4

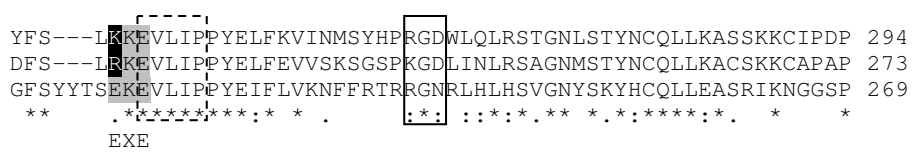

human ART4 mouse ART4

IAIASLSFLTSVIIFSKSRV-------- 314 VVIGCL-FLVTVVISSKSRAQRNLLAPF 300 ASAAI IFP SVI GVF LCLAKQ------- 289

$$
\text { . : . : : . : : }
$$

B human ART4 locus (chromosome 12)

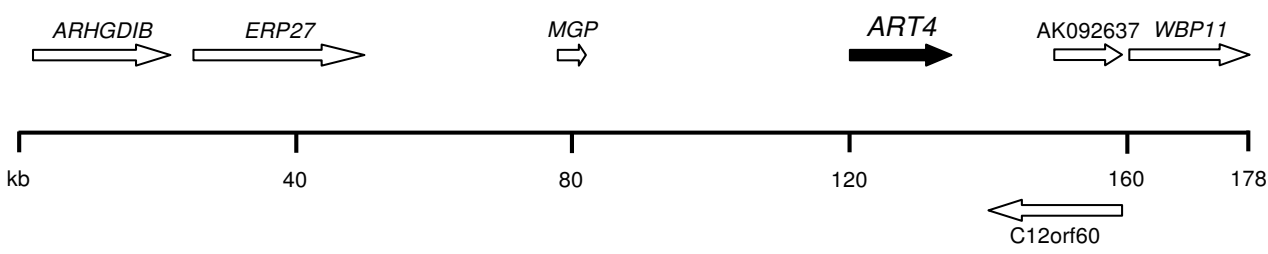

chicken ART4 locus (chromosome 1)

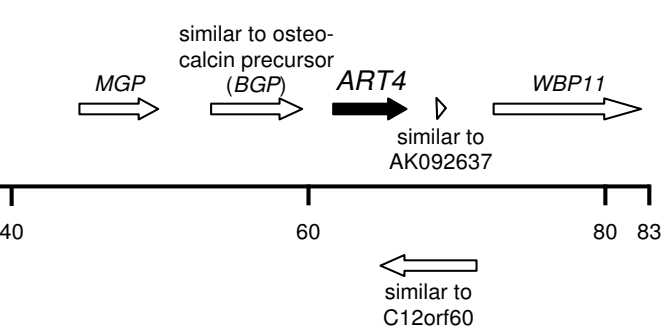

Figure 2

Amino acid sequence alignment of ART4 from men, mice and chicken. A) The deposited amino acid sequences from human ([GenBank: NM02I07I]), mouse ([GenBank: NM026639.2]) and chicken ART4 ([GenBank: XM425453.I]) were aligned using the CLUSTAL W (I.83) multiple sequence alignment program [22]. Residues corresponding to the R-S-EXE motif are shown in grey. Residues that differ from this motif are highlighted in white on black background. The numbering of the amino acids indicates the position of the single amino acids within the respective ART. Boxes indicate putative RGD sequence motifs (solid lines) or stretches of residues that are highly conserved among ARTs (broken lines). " * " marks residues that are identical in all sequences; " : " marks conserved substitutions and ". " marks semi-conserved substitutions. B) Comparison of the human and chicken ART4 loci. The genes are depicted as arrows with the ART4 genes shown as filled arrows. The gene order at the human and chicken loci was obtained from the NCBI map viewer http://www.ncbi.nlm.nih.gov/mapview/ 
on human chromosome 12, which harbours the human ART4 gene (Fig. 2B). The analysed 83-kb Gallus gallus locus comprises seven genes in addition to ART4. Six of these genes were also found surrounding the human ART4 locus, whereas the gene (BGP) directly upstream of chicken ART4 had no human counterpart (Fig. 2B). The data presented so far strongly suggest that the predicted chicken gene is orthologous to mammalian ART4 genes.

\section{Analysis of the 5' and 3' untranslated region}

To analyse the 5' end of the chicken ART4 mRNA we performed 5' inverse RACE-PCR on RNA derived from yolk sack. Among the respective PCR products we obtained a product of 422 bp (data not shown). According to the sequence analysis of the product ([GenBank: EF626644]) which includes exon 1 and parts of exon 2 the 5' UTR consists of $206 \mathrm{bp}$.

The 3' UTR of the chicken ART4 mRNA was analysed by applying 3' inverse RACE-PCR [26] or 3' RACE-PCR [16] on mRNA from HD3 cells using primers derived from the predicted ART4 sequence. As no ART4 specific transcripts were obtained, possibly due to the length of the products we applied conventional RT-PCR analysis to amplify ART4 mRNA reaching into the 3' UTR as far as possible. We obtained a PCR product ([GenBank: EU048538]) of 2199 bp (data not shown) consisting mainly of exon 3 and to a minor extent of exon 2. It contains three obviously unused polyadenylation signals. In a subsequent 3' RACE-PCR analysis using primers derived from the above described PCR product we detected a transcript (GenBank: EU048537]), representing the 3' end of the chicken ART4 mRNA.

Figure 3A combines the genomic DNA and cDNA sequences ([GenBank: EF626644, EU048538, EU048537, and XM425453.1]) to depict the chicken ART4 mRNA. It shows that chicken ART4, as predicted by computer prediction programs $[23,24]$, contains $\mathrm{N}$ - and C-terminal signal peptides, characteristic of extracellular GPI-anchored membrane proteins. The derived chicken ART4 gene structure is shown in Figure 3B.

\section{Chicken ART4 is a GPI-anchored and glycosylated protein} C-33A cells were stably transfected with an expression plasmid containing the sequence of ART4 encoding amino acids 20-289. As shown by FACS analysis about $30 \%$ of the stably transfected cells were fluorescence positive (Fig. 4A). Treatment with PI-PLC resulted in a significant decrease from $30 \%$ to $9.4 \%$ positive cells, indicating the existence of a GPI-anchored protein. Proteins of the supernatant of the PI-PLC treated C-33A cells were separated by SDS-PAGE and ART4 was detected by Western Blot analysis. The apparent molecular weight was $40 \mathrm{kDa}$, about $10 \mathrm{kDa}$ higher than predicted (Fig. 4B). As chicken
ART4 contains five potential N-glycosylation sites we tested whether the higher mass could be due to glycosylation of the protein. We incubated the chicken ART4 containing supernatant with PNGase F, an enzyme that cleaves the amide bonds between GlcNAc and asparagine residues of N-linked glycoproteins [27]. The molecular weight of ART4 detected in the supernatant by Western Blot analysis was about $10 \mathrm{kDa}$ lower than the untreated protein (Fig. 4C), indicating the presence of asparaginelinked glycosyl moieties on chicken ART4. After having probed the membrane with the anti-Flag M2 antibody, the membrane was stained with Ponceau S. As seen in figure 4D there was hardly any difference between the molecular weight of chicken ART4 and PNGase F. However, the anti-Flag antibody only detected chicken ART4 so that any unspecific binding of the antibody to PNGase F can be excluded.

\section{Chicken ART4 is enzymatically active}

In contrast to human ART4 the chicken ART4 contains the R-S-EXE motif, a characteristic for arginine-specific ARTs [6]. ART4 activity was measured by incubating ART4 transfected C-33A cells with etheno-NAD ${ }^{+}$, an analogue of $\mathrm{NAD}^{+}$. Etheno-NAD ${ }^{+}$can be used as an alternative substrate to monitor etheno-ADP-ribosylation of cell surface proteins. The etheno-ADP-ribosylated proteins were visualized by flow cytometry using an etheno-adenosine specific antibody (1G4) [28]. As shown in Figure 5, transient transfection of C-33A cells with chicken ART4 leads to an ADP-ribosylation of cell surface proteins (Fig. 5A, C). Transfection efficiency was monitored by staining the cells with an anti-Flag antibody (Fig. 5B, D). About $14 \%$ of the cells were ART4 positive and about $18 \%$ carried ADP-ribosylated proteins. As seen in Figure 5E ADP-ribosylated proteins are also detectable on chicken erythrocytes indicating that ADP-ribosylation is not only mediated by recombinant ART4 but also occurs endogenously.

To characterize the nature of the linkage between ADPribose and amino acid side chains cells were incubated in the presence of etheno-NAD ${ }^{+}$. Cell lysates were prepared and incubated under conditions known to cleave specifically the linkage of ADP-ribose to thiol groups $(10 \mathrm{mM}$ $\mathrm{HgCl}_{2}$ ), or to arginine (1 $\mathrm{M} \mathrm{NH}_{2} \mathrm{OH}, \mathrm{pH} 7.0$ ) [29,30]. SDS-PAGE followed by Western blot analysis using the $1 \mathrm{G} 4$ antibody [28] revealed that detection by the antibody was not influenced by treatment with $1 \mathrm{M} \mathrm{NaCl}$ (Fig. 6A, lane 2) and $10 \mathrm{mM} \mathrm{HgCl}_{2}$ (lane 4) but was abolished in the presence of $1 \mathrm{M} \mathrm{NH}_{2} \mathrm{OH}$ (lane 3) strongly suggesting that chicken ART4-catalyzed mono-ADP-ribosylation occurred at arginine residues. As a loading control, the membranes were stripped and reprobed with a $\beta$-actin specific antibody (Fig. 6B). 
A

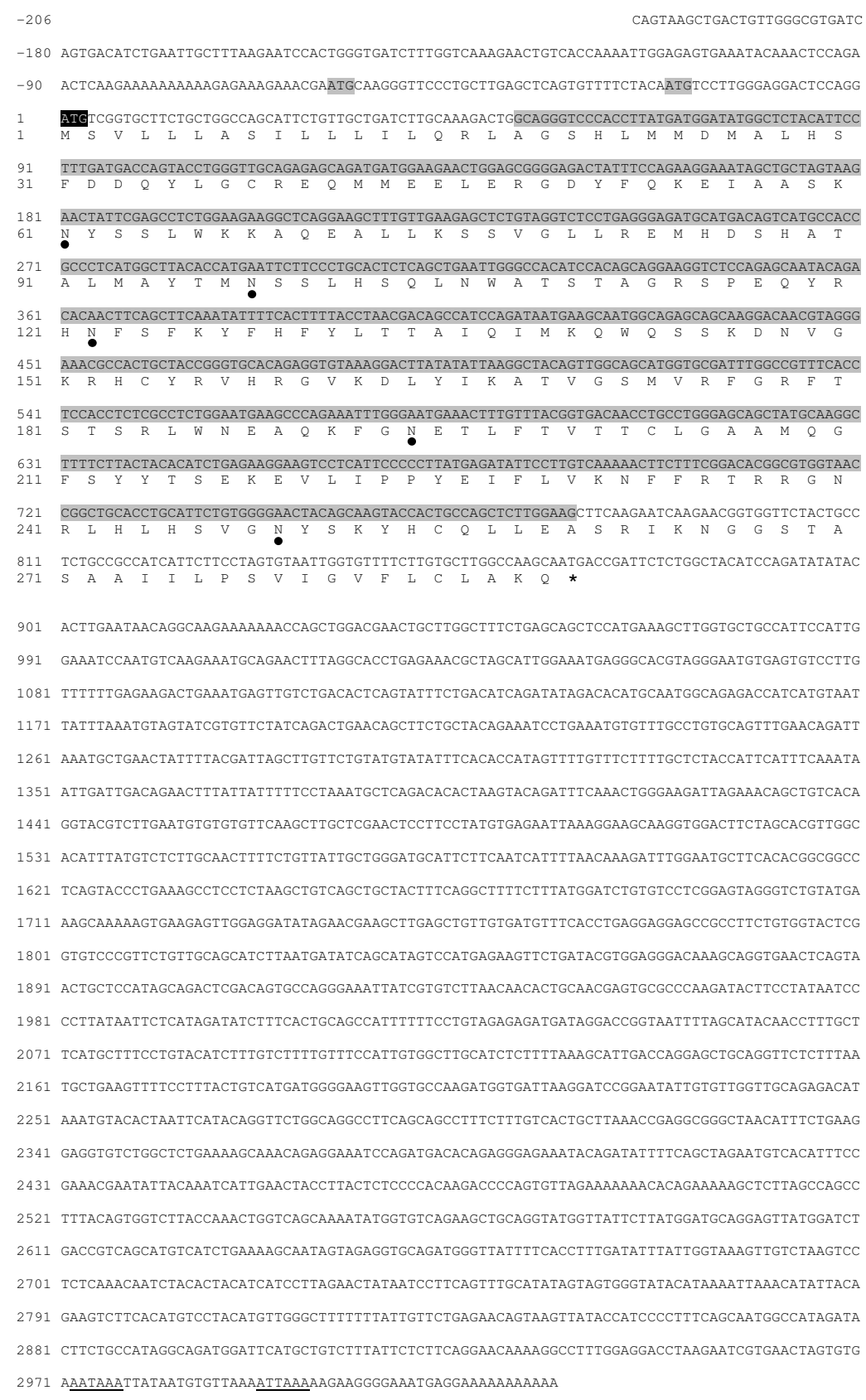

B

257 Exon 1

\section{Figure 3}

Nucleotide- and deduced amino acid sequence of chicken ART4. A) The nucleotide sequence is numbered relative to the initiation codon that is represented by bold white letters on black background. The derived amino acid sequence is shown below the nucleotide sequence. Predicted sites for $\mathrm{N}$-glycosylation are indicated by closed circles. The $\mathrm{N}$ - and $\mathrm{C}$-terminal signal peptides are represented by bold letters. Asterisk indicates the stop codon. Exon 2 is highlighted in grey. ATG codons out of reading frame are indicated by bold black letters on grey background. AAA... (bold) represents the poly A tail of the mRNA and the polyadenylation signal is shown in bold and underlined. B) Schematic representation of the chicken ART4 gene. Exons are indicated by boxes, introns by lines. The lengths of exons and introns are indicated by numbers. 
A

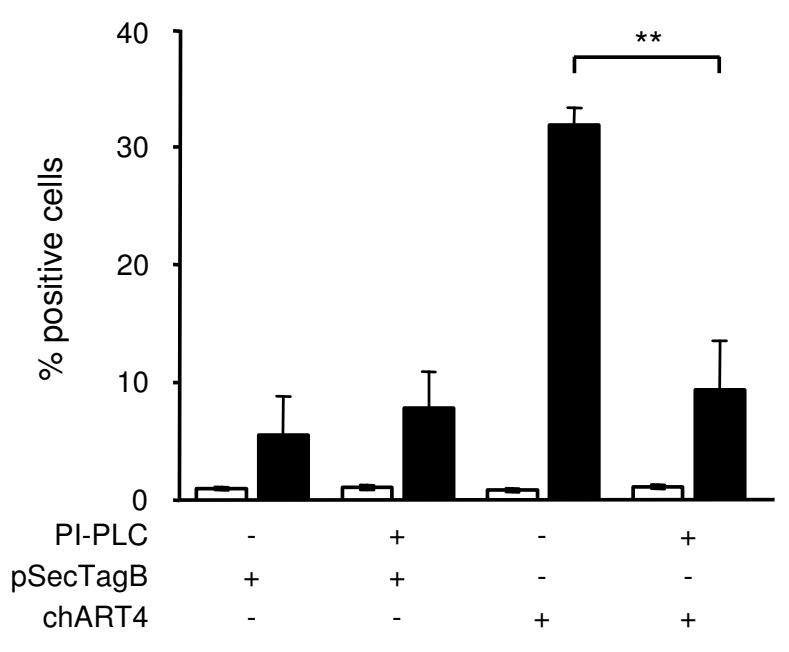

C

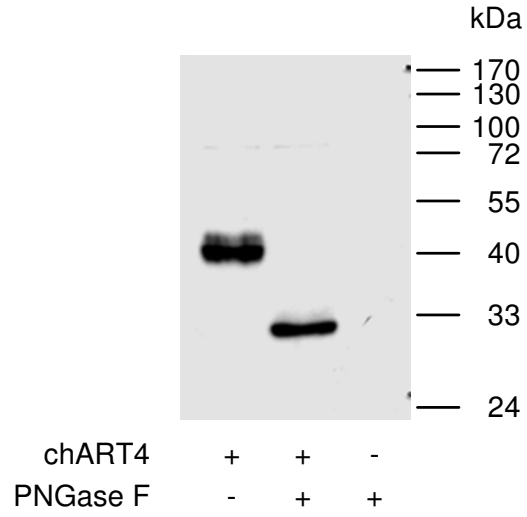

B

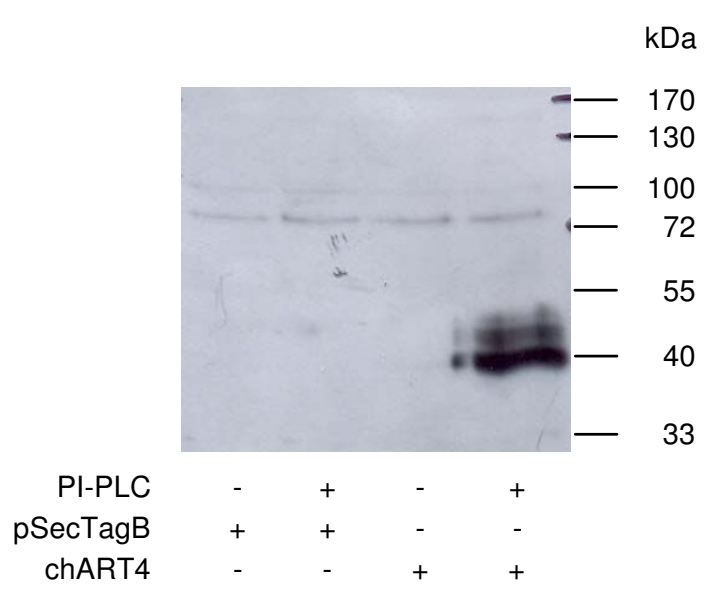

D

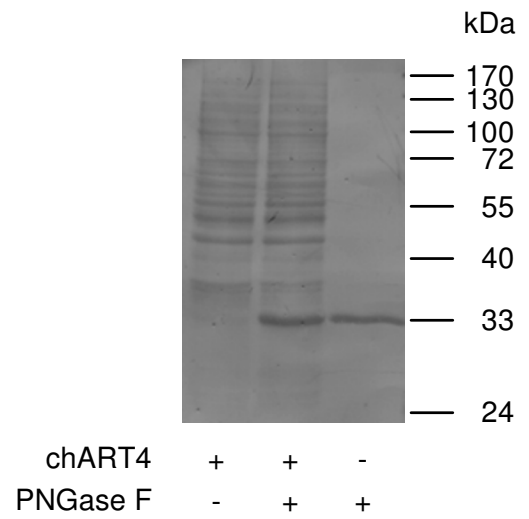

\section{Figure 4}

Treatment of chicken ART4 transfected C-33A cells with PI-PLC and PNGase F. A) C-33A cells (4 $\left.\times 10^{7} / \mathrm{ml}\right)$ transfected with the chicken ART4 containing plasmid or the empty plasmid (pSecTag B) were stained with the anti-Flag antibody (black bar) or the isotype control (white bar) after being incubated for I h at $37^{\circ} \mathrm{C}$ in the presence or absence of PI-PLC $(5 \mathrm{U} /$ $\mathrm{ml})$. Data show the mean of \% positive cells \pm S.E.M. of three experiments. ${ }^{* *} p=0.007$ (Student's t-test) B) Western blot analysis using the anti-Flag antibody was performed with supernatants of chicken ART4 transfected C-33A cells after incubation in the presence or absence of PI-PLC. Data show one representative experiment out of three. C) The supernatant of chicken ART4 transfected cells was incubated for I $\mathrm{h}$ in the presence or absence of PNGase $\mathrm{F}(20000 \mathrm{U} / \mathrm{ml})$ at $37^{\circ} \mathrm{C}$. PNGase $\mathrm{F}$ alone was run as a control. After boiling the samples in SDS-PAGE sample buffer, Western blot analysis using the anti-Flag antibody were carried out. The membrane was stained with Ponceau S (D). Similar results were obtained in three separate experiments.

To verify that arginine-residues were modified by chicken ART4, ADP-ribosylation of poly-L-arginine was determined by incubating chicken ART4 in the presence of [32P]-NAD+, ADP-ribose and poly-L-arginine. ADP-ribose was added to minimize the contribution of the non-enzymatic addition of free [32P]-ADP-ribose to poly-Larginine.
The finding that radioactivity was incorporated in poly-Larginine (Fig. 7) demonstrates that ART4 catalyzed monoADP-ribosylation occurred at arginine residues.

To further characterize chicken ART4 the $\mathrm{K}_{\mathrm{m}}$ value of the enzyme was determined. Recombinant chART4 was used for time- and dose-dependent determinations of enzy- 
A

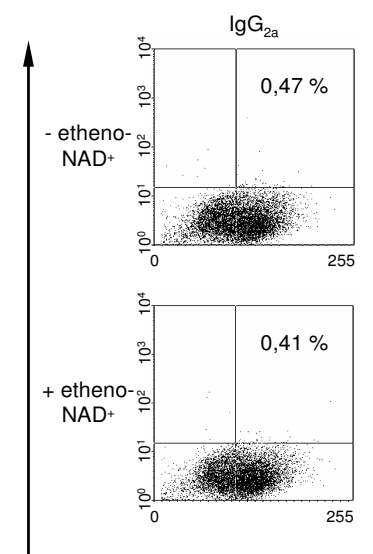

C

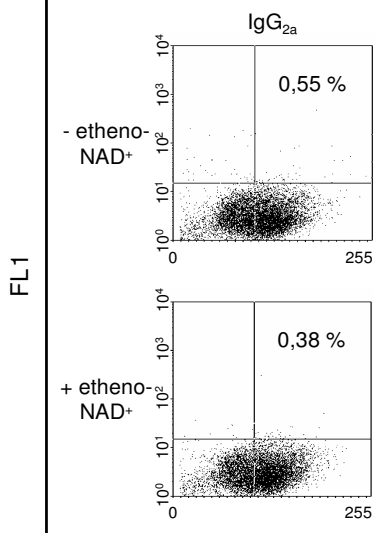

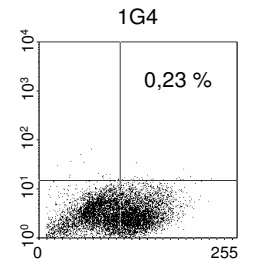
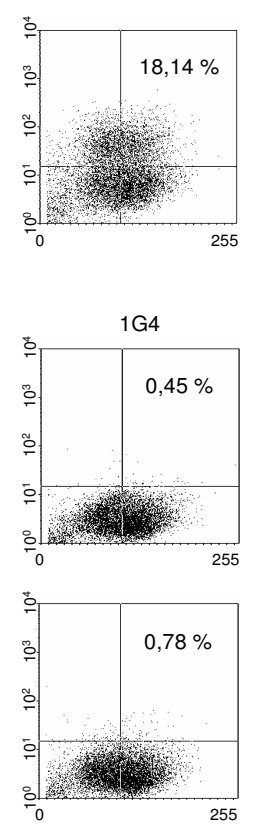

B
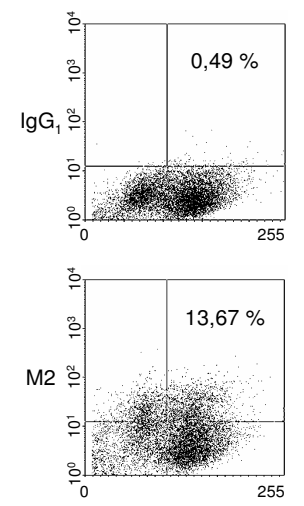

D
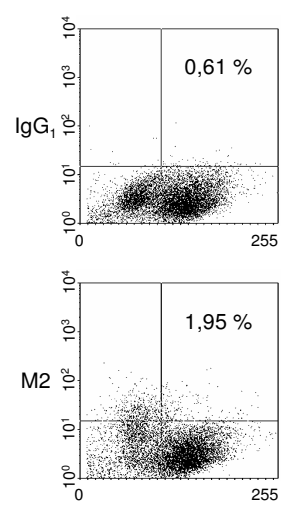

E
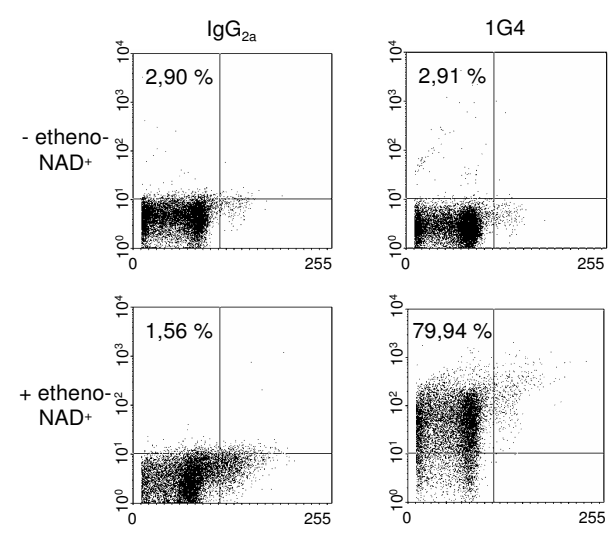

FSC

\section{Figure 5}

Detection of ADP-ribosylated proteins by flow cytometry. C-33A cells $\left(I \times 10^{7} / \mathrm{ml}\right)$ transiently transfected with a Flagtagged chicken ART4 containing plasmid (A, B) or the empty plasmid (PSecTag B) (C, D) were incubated at $37^{\circ} \mathrm{C}$ in the presence or absence of $200 \mu \mathrm{M}$ etheno-NAD for $30 \mathrm{~min}$. After washing, cells were stained with an etheno-adenosine specific antibody (IG4) (A, C) or an anti-Flag antibody (M2) (B, D) and the respective isotype control. Numbers in the upper right quadrant indicate the percentage of fluorescence positive cells. Shown are typical scattergrams (fluorescence (FLI) vs. forward scatter (FSC)) of one representative experiment out of three. (E) Chicken erythrocytes (I\% v/v), isolated by density gradient centrifugation, were treated as described above and stained with the IG4 antibody. Shown is one representative experiment out of 8 . 

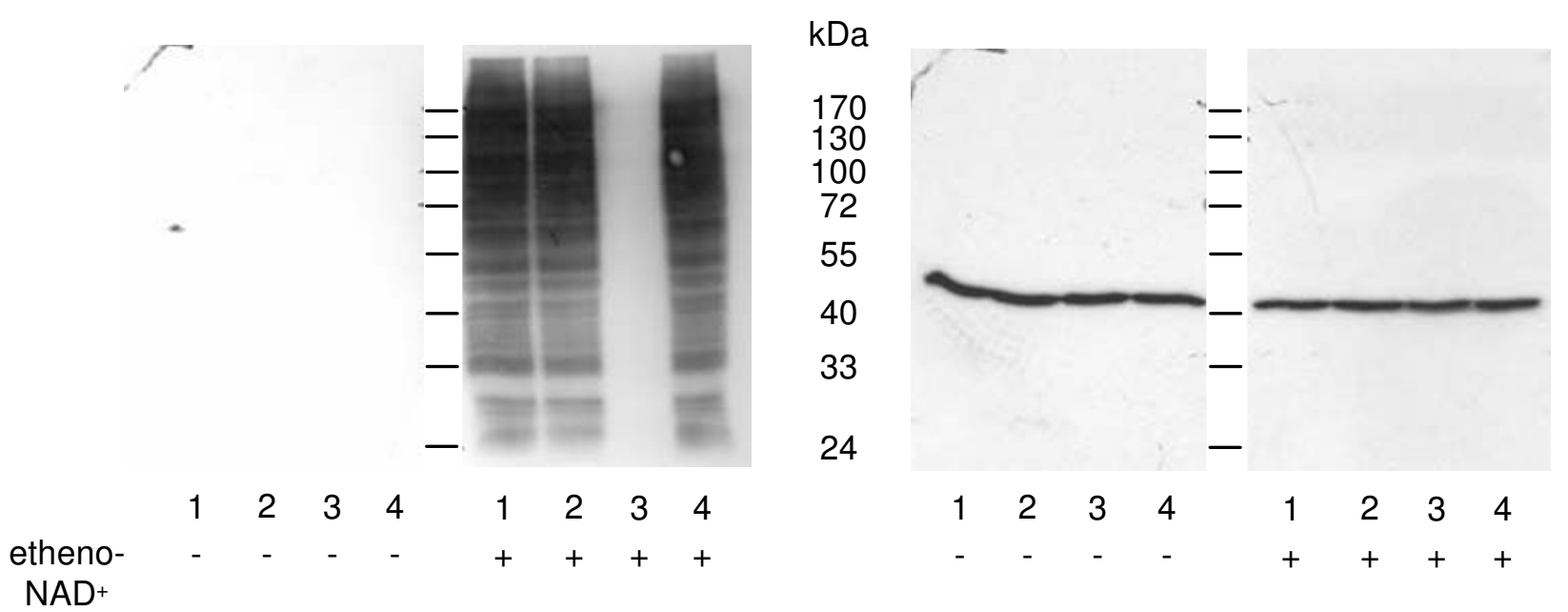

\section{Figure 6}

Effect of $\mathrm{NH}_{2} \mathrm{OH}$ and $\mathrm{HgCl} 2$ on the stability of the ADP-ribose bond. C-33A cells $(\mathrm{I} \times 107 / \mathrm{ml})$ transfected with the chicken ART4 containing plasmid were incubated at $37^{\circ} \mathrm{C}$ in the presence or absence of $200 \mu \mathrm{M}$ etheno-NAD for 30 min. After washing, cells were lysed and either directly precipitated (lane I) or incubated at $37^{\circ} \mathrm{C}$ in the presence of I $\mathrm{M} \mathrm{NaCl}$ (lane 2), I $\mathrm{M} \mathrm{NH}_{2} \mathrm{OH}$ ( $\mathrm{pH} \mathrm{7.0)} \mathrm{(lane} \mathrm{3)} \mathrm{or} 10 \mathrm{mM} \mathrm{HgCl}_{2}$ (lane 4). After $2 \mathrm{~h}$ proteins were precipitated with methanol. All samples were subjected to Western blot analysis using the etheno-adenosine specific antibody $(A)$. After stripping, the blot was reprobed with a beta-actin specific antibody $(B)$. Similar results were obtained in three separate experiments.

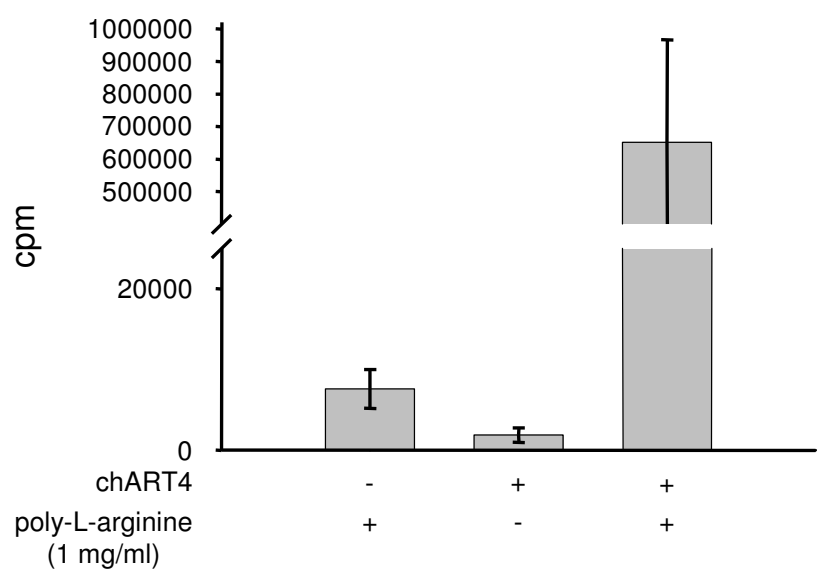

Figure 7

ADP-ribosylation of poly-L-arginine. Recombinant chicken ART4 $(0.7 \mu \mathrm{g})$ was incubated in $100 \mu \mathrm{l}$ PBS containing I mM ADP-ribose, $50 \mu \mathrm{M}$ [32P]-NAD+ $(10 \mu \mathrm{Ci} /$ assay $)$ in the presence or absence of poly-L-arginine $(\mathrm{I} \mathrm{mg} / \mathrm{ml})$ for 30 $\min$ at $37^{\circ} \mathrm{C}$. After incubation the samples were precipitated and collected on Whatman glass-fibre filters as described in the materials and methods. Incorporated radioactivity was measured by liquid scintillation counting. Data show the mean \pm S.D. $(n=3)$. matic activity. Lineweaver-Burk analysis revealed an apparent $\mathrm{K}_{\mathrm{m}}$ for etheno-NAD ${ }^{+}$of $1.0 \pm 0.18 \mu \mathrm{M}$ (mean \pm S.D., $\mathrm{n}=3$ ) of recombinant chART4 (Fig. 8). Treatment of the protein with PNGase F resulted in a decrease in the $\mathrm{K}_{\mathrm{m}}$ value $(0.7 \pm 0.12 \mu \mathrm{M}$; mean \pm S.D., $\mathrm{n}=3)$ which was not significantly different from the $\mathrm{K}_{\mathrm{m}}$ value of the untreated protein ( $\mathrm{p}=0.062$, Student's t-test).

\section{Mutation of the active site motif of human ART4}

To test whether human ART4 containing an R-S-EXE motif is enzymatically active three mutant proteins were constructed and tested for ADP-ribosyltransferase activity using etheno-NAD ${ }^{+}$as substrate. Expression plasmids were generated which encoded for the wildtype ART4, an Y187R mutant, a K242E mutant, and an Y187R, K242E double mutant containing the R-S-EXE motif. C-33A cells were stably transfected with the plasmids and those cells carrying either the wildtype ART4, the single mutants or the double mutant were enriched by cell sorting (more than $90 \%$ positive cells) and used for further analyses. FACS-analysis revealed that neither the mutants carrying a single amino acid exchange nor the double mutant (R-SEXE) displayed any enzyme activity (data not shown). Obviously additional residues besides the intact R-S-EXE motif are involved in catalyzing the enzymatic reaction. 


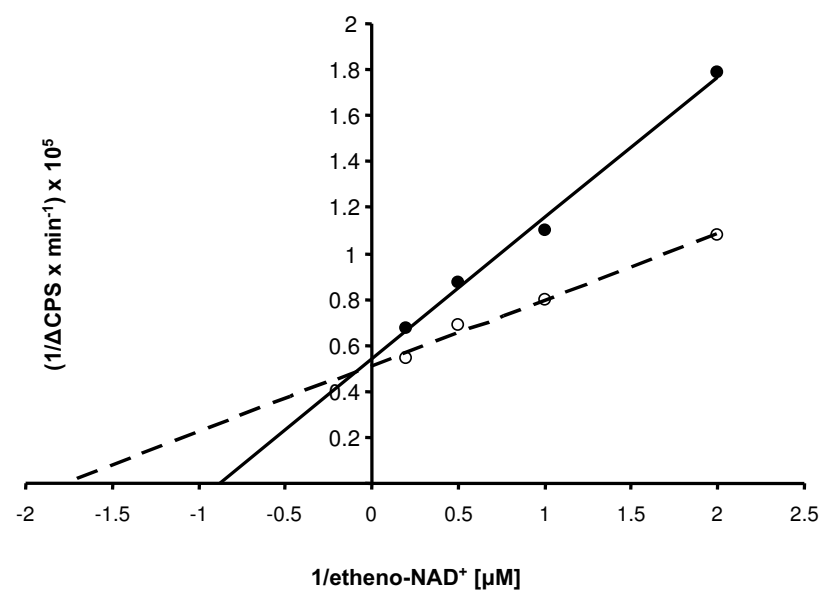

Figure 8

$K_{m}$ determination for etheno-NAD+ of chicken ART4. Recombinant chART4 $(7 \mu \mathrm{g} / \mathrm{ml})$ was incubated at room temperature for $0.5,1.5,2.5,3.5,4.5,5.5,6.5,8,10,12,15,20$, and $30 \mathrm{~min}$ in the presence of poly-L-arginine $(1 \mathrm{mg} / \mathrm{ml})$ and $0.5, \mathrm{I}, 2$, and $5 \mu \mathrm{M}$ etheno-NAD ${ }^{+}$in the presence (open circles) and absence (filled circles) of PNGase F. The ADP-ribosyltransferase activity was determined by measuring the increase in fluorescence intensity. Shown is a double reciprocal plot of the data of the dose response. Data show one representative experiment out of three $\left(\mathrm{K}_{\mathrm{m}}\right.$ "untreated" vs. $\mathrm{K}_{\mathrm{m}}$ "treated" chART4 $\mathrm{p}=0.062$, Student's t-test).

\section{Tissue distribution of chicken ART4}

Quantitative real-time RT-PCR analysis of chicken tissues revealed that the highest amount of chicken ART4 mRNA was present in spleen, liver and bone marrow, while in thymus, bursa of Fabricius, and caecum it was hardly detected. No mRNA was detected in lung (Fig. 9).

\section{Discussion}

Whereas most studies have focussed on ART genes and activity in mammals expression of ARTs has also been demonstrated in chicken. Chicken contain both soluble ARTs (ART6.1 and ART6.2) and GPI-anchored ARTs (cgART1 and cgART2). The nucleotide sequence of $c g A R T 2$ was found to be identical with that of ART7 (ART7.2) and the CDNA of $c g A R T 1$ encoded a polypeptide which represents an ART7 homologue (ART7.1) [31]. The GPIanchored ARTs showed different enzymatic properties than soluble ARTs and the tissue distribution of cgART1 and cgART2 revealed distinct expression patterns [31]. Besides ART6 and ART7 no other ARTs have been identified in chicken so far. Here we show that apart from ART6 and ART7 chicken also express a non chicken-specific ART.

We describe the cloning and characterization of the ART4 (or DO) gene from Gallus gallus. Several lines of evidence,

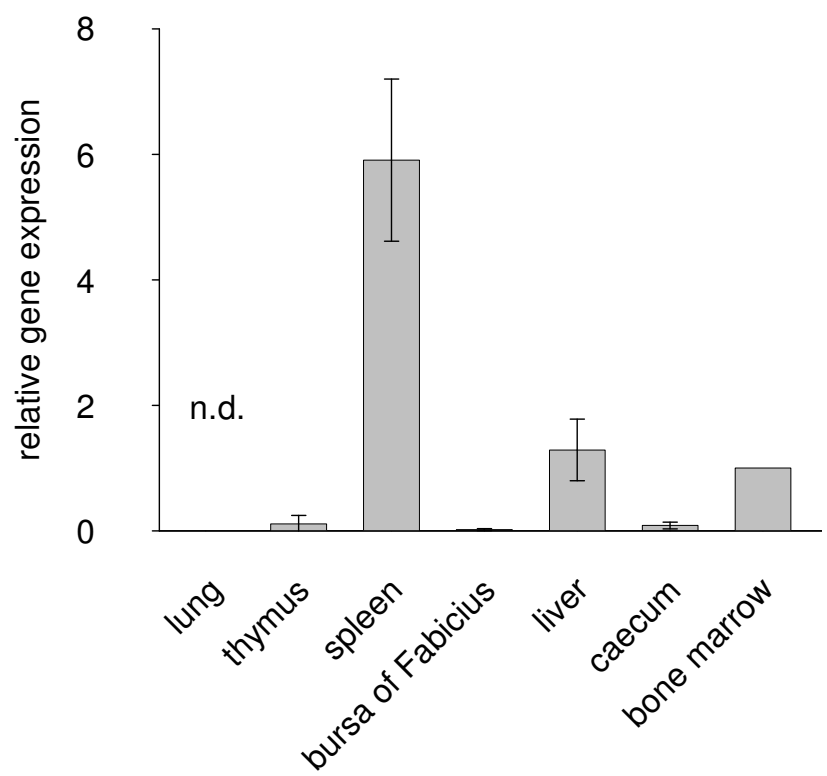

\section{Figure 9}

Real-time RT-PCR analysis of chicken ART4 mRNA expression in different tissues. The mRNA was isolated and mRNA levels of chicken ART4 were measured by quantitative real-time RT-PCR. Levels were standardized to the expression of GAPDH and mRNA concentrations from bone marrow were set as the $100 \%$ reference. Data show the mean \pm S.D. of relative mRNA levels of two individual animals. n.d.: not detectable

such as conserved synteny, similar exon-intron structure, and conserved residues show that the gene cloned is the Gallus gallus orthologue of the human ART4 gene. The predicted chicken ART4 amino acid sequence only shares $47 \%$ and $45 \%$ identity (65\% and $64 \%$ similarity) to human and mouse ART4 respectively and among mammals ART4 also appears to be quite divergent with an identity between human and mouse ART4 of 63\% (75\% similarity). Thus the coding sequence of ART4 appears to be evolving rapidly. Residues that are conserved during evolution in such a rapidly evolving gene or gene family are likely to be important for the function of the protein.

The amino acid sequence alignment of ART4 from chicken, men, and mice uncovered several stretches of residues that are highly conserved, most strikingly the $\mathrm{S}^{30}$ FDDQY $^{35}$ and $\mathrm{K}^{218}$ EVLIPPYE $^{226}$ residues (Fig. 2A). Parts of these sequences namely the FDD and EVLIP motifs are also strictly conserved within other members of the ART family. The FDD sequence motif is located in the $\mathrm{N}$-terminus of the ARTs whereas the EVLIP stretch resides in the $5^{\text {th }}$ of the six conserved $\beta$-strands that make up part of the core features of the ART fold in the catalytic domain. Moreover a lysine residue $(\mathrm{K})$ directly upstream 
of the catalytic E in the EXE motif is found in ART4 of men $\left(\mathrm{KKE}^{244}\right)$, mice $\left(\mathrm{RKE}^{223}\right)$, and chicken $\left(\mathrm{EKE}^{219}\right)$ but not in the EXE motif of other mammalian ARTs [6].

Another common feature of the chicken and human ART4 gene is their genomic organization. Almost the complete mature protein is encoded by exon 2, one of the three exons that besides two introns make up the ART4 gene [10]. Unlike human ART4 mRNA the 3' UTR of the chicken ART4 mRNA comprises 2145 bp. Due to this length the chicken ART4 gene overlaps with a hypothetical gene ([GenBank: XM416185]) located on the opposite DNA strand.

The tissue distribution of chicken ART4 mRNA expression is in part similar to that of human ART4 mRNA [6,7]. Haematological tissues including human fetal liver and human and chicken bone marrow and spleen seem to be preferential sites of ART4 mRNA expression. Furthermore, the fact that HEL cells, a human erythroleukaemia cell line [10] and human erythrocytes carry the ART4 protein and that ART4 mRNA is present in chicken erythrocytes (data not shown) may point to a role of ART4 in haematopoiesis in higher vertebrates.

GPI-anchoring of the chicken ART4 to the membrane was shown by PI-PLC sensitivity. Treatment of chicken ART4 transfected C-33A cells with the enzyme led to the appearance of a $40 \mathrm{kDa}$ protein (Fig. 4B) whose molecular weight was higher than that predicted for chicken ART4 (29 kDa) lacking the $\mathrm{N}$ - and C-terminal signal peptides. The decrease in molecular weight after the exposure to PNGase F strongly suggests that the chicken ART4 is glycosylated. In fact there are five predicted N-glycosylation sites in the amino acid sequence (Fig. 3A).

Determination of the apparent $\mathrm{K}_{\mathrm{m}}$ for etheno-NAD ${ }^{+}$of recombinant chicken ART4 revealed a value of $1.0 \mu \mathrm{M}$. It is similar to the $\mathrm{K}_{\mathrm{m}}(3 \mu \mathrm{M})$ for etheno-NAD ${ }^{+}$of ART2.2 expressed on DC27.10 cells [28] but it differs from the $\mathrm{K}_{\mathrm{m}}$ values for recombinant ART7.2 (130 $\mu \mathrm{M})$ [32] another ART found in chicken and Pseudomonas aeruginosa toxin A (275 $\mu \mathrm{M})$ [33].

Interestingly, both human and chicken ART4 contain an RGD sequence motif. This sequence (Arg-Gly-Asp) found in various adhesive proteins (fibronectin, vitronectin, fibrinogen, and Willebrand factor) serves as a cell attachment site [34]. In chicken the motif $\left(\mathrm{RGD}^{50}\right)$ is found in the N-terminal part of ART4 whereas in humans an $\mathrm{RGD}^{265}$ motif is located in the C-terminus that aligns to the chicken RGN240. In case ART4 should display adhesive properties it would be of interest in how far the cell recognition signal Arg-Gly-Asp is involved in it.
We show that chicken ART4 contains residues corresponding to the R-S-EXE active site motif of arginine-specific ARTs [6] and that it displays arginine-specific enzyme activity while human ART4 shows nonconservative amino acid deviations in this motif. Furthermore, according to the CLUSTAL $\mathrm{W}$ amino acid sequence alignment human and mouse ART4 not only deviate in the glutamic acid (E) two residues upstream of the catalytic glutamic acid (E) of the R-S-EXE motif but also in the arginine (R) which is replaced by histidine $(\mathrm{H})$ in mouse and tyrosine $(\mathrm{Y})$ in men (Fig. 2A).

Considering the importance of the R-S-EXE motif in the catalytic core of all arginine modifying ARTs we exchanged two amino acids of the human ART4 Y-S-KXE motif to obtain an intact R-S-EXE motif. Surprisingly C33A cells expressing human ART4 with the R-S-EXE motif did not display any enzyme activity. Obviously the mere presence of the correct motif in ART4 is not sufficient to turn the protein into an active enzyme. Further mutational studies are necessary to identify additional amino acid residues essential for restoring a functional catalytic core.

It is conceivable that the common ancestor of birds and mammals possesses an enzymatically active ART4 and that the loss of enzyme activity of human ART4 may have arisen due to some evolutionary advantages.

Having cloned and characterized an enzymatically active ART4 orthologue we have provided important experimental tools to elucidate the functional role of ART4. Knowledge of such function in turn may help to explain the loss of ART4 enzyme activity in mammals during evolution.

\section{Conclusion}

Mono-ADP-ribosyltransferases (ARTs) catalyze the transfer of a single ADP-ribose moiety of $\mathrm{NAD}^{+}$to a specific amino acid in a target protein. Mammalian ARTs consist of five members (ART1 - 5) two of them ART3 and ART4 being enzymatically inactive, unlike the active members they do not contain the R-S-EXE motif in the catalytic domain typical of arginine-specific ADP-ribosyltransferases. Here we identified the chicken ART4 as the first real orthologue of a member of the mammalian ARTs in a non-mammalian species. In contrast to the mammalian ART4 the chicken ART4 contains an intact R-S-EXE motif and exhibits the predicted enzyme activity. Thus, ART4 is the first ADP-ribosyltransferase which displays different biochemical properties in two higher vertebrate classes.

\section{Authors' contributions}

AG performed the sequence alignments, carried out the protein and enzymatic experiments, participated in the mRNA analyses and helped to draft the manuscript. SR 
carried out the mRNA analyses and AB the real time RTPCR analyses. FS performed the mutational analyses of human ART4. SH supervised and designed the study with essential contribution by AG, participated in its coordination, and drafted the manuscript. All authors read and approved the final manuscript.

\section{Acknowledgements}

This work was supported by the Deutsche Forschungsgemeinschaft $(\mathrm{Ha}$ 2484/3-I). We thank Dr. Friedrich Koch-Nolte (Institute of Immunology, University Hospital, Hamburg, Germany) for providing the anti-humanART4 and IG4 antibodies and Dr. Thomas Göbel (Institute of Animal Physiology, University of Munich, Munich, Germany) for kindly supplying HD3 cells. Dr. Karin Wiebauer performed the initial database search and we are grateful to her for critical reading of the manuscript and for helpful and stimulating discussions.

\section{References}

I. Okazaki IJ, Moss J: Mono-ADP-ribosylation: a reversible posttranslational modification of proteins. Adv Pharmacol 1996, 35:247-280.

2. Ueda K, Hayaishi O: ADP-ribosylation. Annu Rev Biochem 1985 , 54:73-100

3. Seman M, Adriouch S, Haag F, Koch-Nolte F: Ecto-ADP-ribosyltransferases (ARTs): emerging actors in cell communication and signaling. Curr Med Chem 2004, I I:857-872.

4. Haag F, Koch-Nolte F, Kuhl M, Lorenzen S, Thiele HG: Premature stop codons inactivate the RT6 genes of the human and chimpanzee species. J Mol Biol 1994, 243:537-546.

5. Hollmann C, Haag F, Schlott M, Damaske A, Bertuleit H, Matthes M, Kuhl M, Thiele HG, Koch-Nolte F: Molecular characterization of mouse T-cell ecto-ADP-ribosyltransferase Rt6: cloning of a second functional gene and identification of the Rt6 gene products. Mol Immunol 1996, 33:807-8I7.

6. Glowacki G, Braren R, Firner K, Nissen M, Kuhl M, Reche P, Bazan F, Cetkovic-Cvrlje M, Leiter E, Haag F, et al:: The family of toxinrelated ecto-ADP-ribosyltransferases in humans and the mouse. Protein Sci 2002, II:1657-1670.

7. Gubin AN, Njoroge JM, Wojda U, Pack SD, Rios M, Reid ME, Miller JL: Identification of the dombrock blood group glycoprotein as a polymorphic member of the ADP-ribosyltransferase gene family. Blood 2000, 96:2621-2627.

8. Koch-Nolte F, Haag F, Braren R, Kuhl M, Hoovers J, Balasubramanian $S$, Bazan F, Thiele HG: Two novel human members of an emerging mammalian gene family related to mono-ADPribosylating bacterial toxins. Genomics 1997, 39:370-376.

9. Grahnert A, Friedrich M, Pfister M, Haag F, Koch-Nolte F, Hauschildt $S$ : Mono-ADP-ribosyltransferases in human monocytes: regulation by lipopolysaccharide. Biochem / 2002, 362:717-723.

10. Grahnert A, Friedrich M, Engeland K, Hauschildt S: Analysis of mono-ADP-ribosyltransferase 4 gene expression in human monocytes: splicing pattern and potential regulatory elements. Biochim Biophys Acta 2005, 1730:173-186.

II. Balducci E, Micossi LG, Soldaini E, Rappuoli R: Expression and selective up-regulation of toxin-related mono ADP-ribosyltransferases by pathogen-associated molecular patterns in alveolar epithelial cells. FEBS Lett 2007, 58 I:4199-4204.

12. Haag FA, Kuhlenbaumer G, Koch-Nolte F, Wingender E, Thiele HG Structure of the gene encoding the rat $T$ cell ecto-ADP-ribosyltransferase RT6. J Immunol 1996, 157:2022-2030.

13. Tsuchiya M, Hara N, Yamada K, Osago H, Shimoyama M: Cloning and expression of cDNA for arginine-specific ADP-ribosyltransferase from chicken bone marrow cells. J Biol Chem 1994 269:2745I-27457.

14. Davis T, Shall $S$ : Sequence of a chicken erythroblast mono(ADP-ribosyl)transferase-encoding gene and its upstream region. Gene 1995, 164:371-372.

15. Gebhardt K, Ellerbrock K, Pera I, Ivell R, Kirchhoff C: Differential expression of novel abundant and highly regionalized mRNAs of the canine epididymis. J Reprod Fertil 1999, I 16:39|-402.
16. Frohman MA, Dush MK, Martin GR: Rapid production of fulllength cDNAs from rare transcripts: amplification using a single gene-specific oligonucleotide primer. Proc Natl Acad Sci USA 1988, 85:8998-9002.

17. Young TL, Santella RM: Development of techniques to monitor for exposure to vinyl chloride: monoclonal antibodies to ethenoadenosine and ethenocytidine. Carcinogenesis 1988, 9:589-592.

18. Thiele A, Wasner M, Muller C, Engeland K, Hauschildt S: Regulation and possible function of beta-catenin in human monocytes. Immunol 200I, 167:6786-6793.

19. Altschul SF, Gish W, Miller W, Myers EW, Lipman DJ: Basic local alignment search tool. J Mol Biol 1990, 21 5:403-4I0.

20. Altschul SF, Madden TL, Schaffer AA, Zhang J, Zhang Z, Miller W, Lipman D]: Gapped BLAST and PSI-BLAST: a new generation of protein database search programs. Nucleic Acids Res 1997, 25:3389-3402.

2I. Florea L, Hartzell G, Zhang Z, Rubin GM, Miller W: A computer program for aligning a cDNA sequence with a genomic DNA sequence. Genome Res 1998, 8:967-974.

22. Thompson JD, Higgins DG, Gibson TJ: CLUSTAL W: improving the sensitivity of progressive multiple sequence alignment through sequence weighting, position-specific gap penalties and weight matrix choice. Nucleic Acids Res 1994, 22:4673-4680.

23. Bendtsen JD, Nielsen H, von Heijne G, Brunak S: Improved prediction of signal peptides: SignalP 3.0. J Mol Biol 2004, 340:783-795

24. Fankhauser N, Maser P: Identification of GPI anchor attachment signals by a Kohonen self-organizing map. Bioinformatics 2005, 21 : | $846-1852$

25. Altschul SF, Wootton JC, Gertz EM, Agarwala R, Morgulis A, Schaffer $A A, Y u$ YK: Protein database searches using compositionally adjusted substitution matrices. FEBS J 2005, 272:5I0I-5I09.

26. Friedrich M, Grahnert A, Hauschildt S: Analysis of the 3' UTR of the ART3 and ART4 gene by 3' inverse RACE-PCR. DNA Seq 2005, I 6:53-57.

27. Maley F, Trimble RB, Tarentino AL, Plummer TH Jr: Characterization of glycoproteins and their associated oligosaccharides through the use of endoglycosidases. Anal Biochem 1989, 180:195-204.

28. Krebs C, Koestner W, Nissen M, Welge V, Parusel I, Malavasi F, Leiter EH, Santella RM, Haag F, Koch-Nolte F: Flow cytometric and immunoblot assays for cell surface ADP-ribosylation using a monoclonal antibody specific for ethenoadenosine. Anal Biochem 2003, 314:108-II5.

29. Payne DM, Jacobson EL, Moss J, Jacobson MK: Modification of proteins by mono(ADP-ribosylation) in vivo. Biochemistry 1985 , 24:7540-7549.

30. Meyer T, Koch R, Fanick W, Hilz H: ADP-ribosyl proteins formed by pertussis toxin are specifically cleaved by mercury ions. Biol Chem Hoppe Seyler 1988, 369:579-583.

31. Terashima M, Osago H, Hara N, Tanigawa Y, Shimoyama M, Tsuchiya M: Purification, characterization and molecular cloning of glycosylphosphatidylinositol-anchored arginine-specific ADP-ribosyltransferases from chicken. Biochem J 2005, 389:853-861.

32. Davis T, Sabir JS, Tavassoli M, Shall S: Purification, characterisation, and molecular cloning of a chicken erythroblast mono(ADP-ribosyl)transferase. Adv Exp Med Biol 1997, 4I9:145-I54.

33. Armstrong S, Merrill AR: Application of a fluorometric assay for characterization of the catalytic competency of a domain III fragment of Pseudomonas aeruginosa exotoxin A. Anal Biochem 200I, 292:26-33.

34. Ruoslahti E, Pierschbacher MD: Arg-Gly-Asp: a versatile cell recognition signal. Cell 1986, 44:5 I7-5I8. 